\title{
Introdução à metodologia didática em dança de Rolf Gelewski
}

Introduction to the didactic methodology in dance by Rolf Gelewski

Paulo Baeta ${ }^{1}$

1.

Professor na Universidade Federal de Minas Gerais. Contato:

paulobpereira@uol.com.br ORCID: http://orcid.org/ 0ooo-0002-9236-3903

Submetido em: 06/10/2016, aceito em: 03/11/2016. 
O tema escolhido para a pesquisa de pós-doutorado "O aprofundamento e a elaboração da Metodologia Didática em Dança de Rolf Gelewski" continua vibrando em mim. O trabalho didático em dança elaborado e desenvolvido por Rolf é extremamente amplo. A conclusão não representa necessariamente algo fechado; ela pode muito mais: seguindo a pesquisa, representar novas sugestões, propostas, olhares e compreensões diferentes a serem desenvolvidas e criadas adiante no mesmo tema. Vários materiais didáticos criados por ele ainda não foram publicados, e outros muito pouco desenvolvidos pedagogicamente. Se ele hoje estivesse vivo, teria 86 anos de idade. Seu trabalho teórico e prático teria certamente uma forte presença em todo o Brasil, tanto em dança como na área de educação artística. Falo disso, porque sua energia como criador artístico e pedagogo era muito intensa. Buscando nos arquivos da Casa Sri Aurobindo ${ }^{2}$ todos os documentos, publicações, materiais de trabalho e anotações de Rolf, podemos perceber a riqueza dos trabalhos já feitos por ele e ainda "em aberto": criação de centros de estudo e educação em arte e desenvolvimento da consciência humana, propostas de seminários, palestras, cursos, exposições e espetáculos de dança, estruturas de textos e propostas didáticas a serem publicadas, e muito mais informações ainda por serem analisadas e desenvolvidas.

Sobre a importância de Rolf como professor, artista e coreógrafo em dança, quero chamar a atenção do livro publicado por Carmen Paternostro Schaffner intitulado "A dança expressionista: Alemanha e Bahia” (SCHAFFNER, 2012). Em seu livro ela acentua o significado da importância dele na formação e elaboração da Escola de Dança da Universidade Federal da Bahia (UFBA).

Um outro livro importante é "Rolf Gelewski e a improvisação na criação em dança: formas, espaço e tempo", de Juliana Cunha Passos (2015). Mesmo não tendo conhecido Rolf ela é a pessoa, na área de dança, que mais acompanhou e desenvolveu o trabalho didático dele. Em seus estudos de dança na Universidade Estadual de Campinas (Unicamp) ela desenvolveu duas iniciações científicas, no curso de graduação em dança, o mestrado e, recentemente, o doutorado, inspirados e elaborados pelo material metodológico dele. Todos esses projetos foram orientados pela professora Dra. Elisabeth Bauch Zimmermann, do Instituto de Artes da Unicamp.

Elisabeth se formou em dança na UFBA com a presença de Rolf (1968-1972), tendo sido por muito tempo sua secretária e assistente, e também membro fundador da Casa Sri Aurobindo. Em 2015, ela completou sua livre docência com o
2.

Sri Aurobindo: pensador, filósofo e escritor indiano. https://en.wikipedia.org/ wiki/Sri_Aurobindo: The American philosopher Ken wilder has called Aurobindo "India's greatest modern philosopher sage" /Casa Sri Aurobindo - CASA: núcleo para o livro desenvolvimento da consciência. www.casasriaurobindo.com.br 
título: "A dança na formação do indivíduo: relacionando os métodos de criação em dança de Rolf Gelewski e Rudolf von Laban com temas da Psicologia Analítica Junguiana sobre a natureza humana".

\section{Quem foi Rolf Gelewski?}

Rolf Gelewski foi o introdutor e organizador das bases curriculares do primeiro curso superior de dança do país, na Universidade Federal da Bahia (UFBA), a partir de 1960, na qual, em 1962, ele fundou o Grupo de Dança Contemporânea da UFBA, onde atuou como coreógrafo e diretor artístico até o final de 1971.

Ele nasceu em 7 de abril de 1930 na Alemanha e formou-se e desenvolveu seu trabalho de dança criativa em Berlim, sobretudo com Mary Wigman, Marianne Vogelsang e Gret Palucca, entre 1950 e 1960. Nesse período trabalhou como professor de dança em universidades e como bailarino solista no Teatro Metropolitano de Berlim. Apresentou também seus próprios espetáculos como solista. Foi assim que preparava seus ensaios na Escola de Mary Wigman. Ganhou nesta época dois prêmios por sua atuação como dançarino solista.

Mudou-se então, em 1960, para o Brasil, a convite do Reitor Edgar Santos da Universidade Federal da Bahia. Foi aí que ele estruturou o curso de dança desta universidade, com foco em dança moderna. De 1960 a 1975 ocupou os cargos de Diretor da Escola de Dança, Dirigente e Coreógrafo do Grupo de Dança Contemporânea e, finalmente, de Chefe do Departamento de Integração e Educação Artística. Como diretor e professor da Escola de Dança, estruturou e pôs em prática vários métodos didáticos referentes ao ensino de improvisação, composição, coreografia em grupo, estudo de formas, estudos do espaço e rítmica, sempre avaliando a dança como um meio para o desenvolvimento da consciência e autoevolução. Publicou pela UFBA os métodos "Rítmica Métrica" (1967) e "Estudo Básico de Formas" (1971) e criou e desenvolveu a disciplina "Filosofia da Dança". Foi professor convidado nos $4^{\circ}$ e $5^{\circ}$ Festivais de Inverno da UFMG (1970/71), em Ouro Preto.

Desde 1960 Rolf criou recitais solistas no Brasil, mantendo também suas apresentações na Alemanha, Áustria e Estados Unidos. Com o Grupo de Dança Contemporânea da Escola de Dança da UFBA, ele apresentava espetáculos tanto em Salvador como em outras cidades do Brasil.

Entre 1967 e 1971 Rolf foi convidado pelo Instituto Goethe para várias turnês como dançarino solista e professor de dança criativa através da Índia e das Filipinas, e também minis- 
trando cursos de dança como professor convidado em universidades norte-americanas. Foi em função dessas turnês pela Índia que, a convite do Instituto Goethe, apresentou seu recital solístico no Teatro do Sri Aurobindo Ashram, o que gerou uma mudança decisiva em sua vida pessoal, assim como artística e pedagógica. Esta experiência provocou nele, mais decisivamente, a descoberta de dimensões interiores através da dança.

\section{Meu contato e minha experiência com Rolf}

Foi em 1970 que eu o conheci e, por sua indicação, fui contratado como bailarino do Grupo de Dança da UFBA. Em 1971, Rolf criou em Salvador a Casa Sri Aurobindo, da qual eu fui um dos fundadores. Deste ano até 1979 trabalhei primeiramente como um de seus alunos, e em seguida, como um de seus assistentes. Desde o seu período na UFBA até seu falecimento em 1988, ele desenvolveu seus materiais didáticos como coreógrafo e professor de dança, e também - muito inspirado pela visão integral de Sri Aurobindo - desenvolveu um trabalho educativo que busca desenvolver o ser humano desde o físico até a percepção contemporânea mais consciente, sobretudo nas dimensões artística, educativa e espiritual.

Tendo trabalhado diretamente com Rolf Gelewski como bailarino, aluno de dança e professor assistente por vários anos, desenvolvi grande parte do meu trabalho pedagógico de dança criativa, espontânea e contemporânea baseado em seus métodos.

Atualmente sou professor na Escola de Belas Artes da UFMG no curso de Licenciatura em Dança, onde fundamento várias de minhas disciplinas na estrutura metodológica de Rolf Gelewski e oriento alunos em Projetos de Extensão e Pesquisa no desenvolvimento de sua pedagogia. Assim, o interesse desta pesquisa é continuar elaborando e aprofundando o processo criado por ele, com a finalidade de divulgar, publicar e dar visibilidade à sua experiência e seu material pedagógico e criativo já existente, parcialmente editado e raramente conhecido.

\section{A metodologia didática em dança de Rolf Gelewski}

Existem poucos livros e artigos didáticos e pedagógicos publicados - especialmente em português - sobre Rolf Gelewski. Por isto, levo atenção a uma necessidade urgente de publicar os textos e exercícios didático-pedagógicos de Rolf já existentes e ainda não editados, e outros editados, mas esgotados. Muitos deles representam uma compreensão pedagógica raramente inexistente. 
Apresento então a seguir um exemplo de cada um dos textos e exercícios originais do Rolf, ou variações criadas por mim e por outros assistentes dele, para termos uma compreensão mais clara do seu material didático. Seus textos e exercícios aqui apresentados poderão posteriormente ser usados como material de divulgação ou para publicação em livros, artigos, imagens (desenhos, fotos, ilustrações), filmes, gravações, expondo a riqueza e amplitude do material artístico e pedagógico de Rolf Gelewski. Reconheço a função da pesquisa de pós-doutorado em desenvolvimento no sentido de disponibilizar esse material didático de Rolf para outros pesquisadores na área da arte e da educação em arte, sobretudo para professores de dança.

\section{I - Técnica Corporal}

No Grupo de Dança Contemporânea da UFBA, além de diretor e coreógrafo, Rolf era professor de técnica de dança. Seu exercício técnico foi criado por ele mesmo, a partir da percepção de seu corpo. A aula durava duas horas por dia, semanalmente, de segunda a sexta feira.

A partir da criação da Casa Sri Aurobindo (CASA), começou a dar aulas de técnica corporal para a comunidade da CASA. As aulas eram diárias. Aos poucos ele passou essas aulas para uns de nós, cada um como professor-assistente, seguindo seus exercícios. A partir daí começou a criar cursos específicos para o desenvolvimento da consciência corporal como exercícios de dança. Mais tarde, criou seminários de estudos abertos ao público, diretamente ligados ao seu trabalho didático. Seguindo sua orientação metodológica, os materiais propostos se referiam a: eixo do corpo, pontos de apoio, consciência da totalidade do corpo e seus detalhes, isolamentos, juntas, força e sensibilidade, e muitas outras possibilidades de desenvolvimento corporal e sensível.

Posso imaginar que a identificação dele com as aulas com suas mestras Mary Wigman, Mariane Vogelsang e Gret Palucca deve ter marcado o desenvolvimento de seu trabalho em dança. A ideia inspiradora inicial de sua técnica para o preparo corporal foi a de manter e desenvolver o potencial criativo dos estudantes e bailarinos da UFBA. Posteriormente, seus exercícios foram difundidos para diversos outros lugares de formação em dança. Seus exercícios de técnica iniciavam na barra, desenvolvendo-se no centro da sala, no chão e no espaço.

- Exercícios no chão

A seguir apresento um exemplo de um dos exercícios de Rolf no chão, anotado por mim. Da mesma maneira decidi 
descrever um dos exercícios, porque desta forma se apresenta uma outra maneira de compreensão de exercícios corporais usados em técnicas já conhecidas.

\section{TRABALHO NO CHÃO}

Sentado, pernas dobradas, mãos segurando os joelhos, tronco relaxado sobre as pernas.

a)

- em 1 tempo, curvar a coluna para trás, rolando o quadril (soltar as mãos).

- em 1 tempo volta à posição anterior, e insista com o corpo uma vez na posição inicial. (tudo 4 vezes).

b)

- em 1 tempo, curvar a coluna para trás, rolando o quadril (soltar as mãos). - em 1 tempo esticar todo o corpo (pernas e braços também) deitando.

- em 1 tempo voltar à posição média (anterior).

- em 1 tempo voltar à posição inicial. (tudo 4 vezes).

c)

- em 1 tempo esticar todo o corpo (pernas e braços também) deitando. - em 1 tempo voltar à posição inicial. (tudo 4 vezes).

d)

- em 1 tempo curvar a coluna para trás, rolando o quadril, soltando os joelhos, mantendo o joelho direito no lugar, e esticando a perna esquerda.

- em 1 tempo esticar a coluna verticalmente ao chão, pegando com as mãos a perna direita, aproximando a coluna da coxa direita.

- insistir 2 vezes a aproximação da coluna com a coxa direita.

- em 1 tempo curvar a coluna para trás, rolando o quadril (como anterior). - em 1 tempo esticar a coluna verticalmente ao chão (como anterior).

- em 1 tempo deixar o tronco cair para a frente em cima das pernas (perna direita também estica).

- repetir a mesma coisa no outro lado do corpo.

e)

- em 1 tempo curvar a coluna para trás, rolando o quadril (como anterior). - em 1 tempo esticar a coluna verticalmente ao chão (como anterior).

- em 1 tempo deixar o tronco cair para a frente em cima das pernas (perna direita também estica). (tudo 4 vezes).

- repetir a mesma coisa no outro lado do corpo.

f)

- mantendo o tronco sobre as pernas, em 4 tempos alongar para a frente a perna direita e puxar para trás a perna esquerda (com as mãos segurando os pés).

- em 4 tempos insistir torcendo o tronco para o lado esquerdo, arqueando todo este lado para o alto.

- repetir a mesma coisa no outro lado do corpo.

g) - soltar o corpo, deitar e relaxar. 
O objetivo desse "estudo de formas" é inteiramente didático. $\mathrm{Na}$ base de distinções elementares de forma, resultante de processos reflexivos, desenvolvendo-se exercícios que procuram transferir princípios válidos universalmente e referentes a qualidades de forma, para a prática da dança. Pesquisam-se as possibilidades do corpo humano de realizar formas distintas, voltando-se toda a atenção para o corpo singular e até para partes isoladas do mesmo; porque o intuito é disciplinar o físico do estudante de dança e despertar seu interesse no que diz respeito ao uso do próprio corpo como recurso de configuração (GELEWSII, 1971, p. 1).

Esta citação é o início da Introdução do livro de Rolf, editado pela Universitas (UFBA), "Estudo Básico de Formas: distinções elementares de formas aplicadas em exercícios de movimentação" (GELEWSKI, 1971). Além da elaboração dos exercícios, Rolf discutia com os alunos textos específicos referentes às reflexões sobre a forma. No capítulo "Reflexões sobre a forma" ele escreve: "Nas atuais condições do mundo, as riquezas e profundezas interiores não se podem tornar comunicações perceptíveis, se não através de sua transformação em formas" (p. 4).

Os exercícios se dividiam em três distinções antagônicas, que se referem às qualidades básicas de forma escolhidas por Rolf:

- contraído - dilatado

- simétrico - assimétrico

- curvo - reto.

Em cada uma dessas três distinções existem vários exercícios que podem ser usados como improvisação, ou como fixação (composição ou coreografia), e elaborando as formas de maneira individual ou em grupo.

Na Nota 3 ele escreve: "Cada exercício exige do aluno uma realização individual” (p. 9), e na Nota 4 ele dá uma explicação sobre os exercícios que eu considero muito importante na compreensão do trabalho:

A realização prática das "distinções" é efetuada através de exercícios elaborados com o intento de criar exemplos e modelos, podendo os mesmos serem variados, diminuídos, aumentados, agrupados de outra maneira, interpretados ou até substituídos, pela introdução de novos exercícios (GELEWSKI, 1971, p. 10).

Ele acrescenta: "Recomenda-se, especialmente, transformar uma parte dos exercícios que se referem todos a realizações individuais, em exercícios em grupo" (p. 10).

Há um dos exercícios da Distinção 2 (simétrico - assimétrico) que proponho frequentemente em minhas aulas referentes ao "Estudo de Formas". Eu o considero uma das "joias 
preciosas" de Gelewski, tanto pela possível simplicidade de proposta, como pela variedade imensa que pode desenvolver, chegando até mesmo à criação de uma composição ou coreografia. Apresento aqui, como exemplo, uma parte da explicação do exercício.
E $2 e$ - fix (exercício $2 \mathrm{e}$ - fixação)
PI (posição inicial) - conforme combinação.
1 - Criar para cada uma das letras (vogais e consoantes) assina- ladas a seguir, uma situação parcial característica formada exclusi- vamente pelo conjunto das duas mãos, sendo que se deve explorar especialmente, as inúmeras possibilidades de criar formas interes- santes através de coordenações distintas dos dedos. Representar (simbolizar) as vogais através de situações simétricas e as conso- antes através de situações assimétricas (GELEWSKI, 1971, p. 26).

Rolf propõe neste exercício cada pessoa (ou cada grupo) usar duas palavras antagônicas, pela capacidade de sugerir um contraste de compreensão, intenção, sensibilidade e força criativa. Neste exercício ele mesmo sugere as seguintes palavras:

TREVA / LUZ

CAOS / ORDEM

ÓDIO / AMOR

GUERRA / PAZ

Realizar as seguintes fases de trabalho:

a - sentado, apresentar as letras constantes da combinação escolhida de palavras, uma por uma, sem ritmo determinado, mas evidentemente na sucessão prescrita pelas palavras, separando uma letra da outra por meio de um relaxamento de mãos e braços; $\mathrm{b}$ - sentado, em andamento tranquilo, interligar as letras pertencentes às palavras, por meio de movimentos simples e orgânicos, procurando concatenar as situações simbólicas da maneira mais direta possível; depois de ter representado a primeira palavra, relaxar braços e mãos, para iniciar em seguida a realização da segunda palavra;

c - sentado, concatenar as letras das palavras agora de maneira livre, demorando-se conscientemente na realização dos movimentos de interligação, devendo porém, as situações simbólicas constituírem os pontos culminantes dos movimentos de interligação tanto em relação a sua coordenação formal e rítmica como também no que diz respeito à intensidade de sua realização; em contrário aos itens a- e b- , movimentos do tronco, dos ombros e da cabeça da pessoa executante devem desta vez, participar efetivamente da realização do estudo que deve possuir um ritmo específico elaborado cuidadosamente; d - de pé, sem sair em princípio do lugar, transformar o estudo elaborado segundo as instruções assinaladas na letra c- em um estudo com idênticas estruturas rítmica e formal, sem porém, que se deve incluir agora as possibilidades de movimentação e de forma, que 
quadris, pernas e pés oferecem. Deve-se admitir que o estudo c-, que serve de base para a elaboração deste, sofra alterações determinadas, pela aplicação dos movimentos de quadris, pernas e pés; e - ainda sobre a mesma combinação de palavras, elaborar um estudo completamente livre, em que se substitui os movimentos de interligação por sequências de movimentos, devendo porém, as situações que representam as letras, ocuparem lugares de destaque, na composição do estudo. Deve-se exigir, na realização dessa pequena coreografia, a utilização consciente do espaço e de estruturas rítmicas características.

Em conversa com seus alunos, o professor deve procurar definir e formular o significado de cada palavra bem como de suas coordenações. Na realização das fases a- a e- que representam uma evolução gradativa de "simples" para "complexo", a aplicação de dinâmica e expressão deve corresponder à crescente liberdade; estes meios de configuração deveriam tornar os estudos, em proporção crescente, manifestações claras das significações das palavras (GELEWSIKI, 1971, Pp. 27 a 29).

\section{III - Rítmica Métrica}

Rolf apresentava uma variedade enorme de exercícios didático-pedagógicos relacionados com o ritmo, mas a principal metodologia criada exclusivamente por ele foi o que ele chamou inicialmente de "Rítmica Métrica" (GELEWSKI, 1967). Em 1986 ele editou um outro livro, "Proporção e Precisão: um método de rítmica com base em metros gregos", desenvolvendo esta disciplina. Os metros gregos se referem aos valores de tempo relacionados a longura e brevidade. Os exercícios podem ser desenvolvidos individualmente ou em grupos.

O material exclusivo dos exercícios que se seguem, constitui-se de metros gregos; originários da língua grega, representam relações rítmicas de natureza tão fundamental e pura, que se pode denominá-los "fórmulas rítmicas básicas". Os elementos de que se compõe cada uma dessas fórmulas, das quais existe um número relativamente pequeno, são apenas dois: trata-se de dois valores de tempo que, de acordo com a respectiva terminologia, queremos chamar de "longura" e "brevidade" (GELEWSKI, 1986, p. 7).

Rolf usou dois sinais como anotação destes valores: Longura Brevidade $\mathbf{u}$

Na Nota 1 de seus dois livros (1971 e 1986) segue-se a seguinte informação básica da estrutura métrica: "Determinamos como relação proporcional de brevidade e longura, a relação geralmente aplicada no uso de metros gregos, ou seja: 1:2, o que significa que a longura tem o comprimento (duração) duplo da brevidade: (u : - = 1:2)." 
Na Nota 2 seguem os metros gregos que ele optou na aplicação dos exercícios:

$\begin{array}{lll}\text { 1. } & \text { dáctilo } & -\mathbf{u} \mathbf{u} \\ \text { 2. } & \text { anapesto } & \mathbf{u} \mathbf{u}- \\ \text { 3. } & \text { anfíbraco } & \mathbf{u}-\mathbf{u} \\ \text { 4. } & \text { espondeu } & -- \\ \text { 5. } & \text { tríbraço } & \mathbf{u} \mathbf{u} \mathbf{u} \\ \text { 6. } & \text { troqueu } & -\mathbf{u} \\ \text { 7. } & \text { jambo } & \mathbf{u}- \\ \text { 8. } & \text { pirríquio } & \mathbf{u} \mathbf{u} \\ \text { 9. } & \text { crético } & -\mathbf{u}- \\ \text { 10. } & \text { coriambo } & -\mathbf{u} \mathbf{u}-\end{array}$

Rolf desenvolveu seus exercícios desde o mais simples (aplicando um só metro) até os mais complexos - com mais metros, usando diferentes maneiras de usar as durações palmas, bater os pés no chão, instrumentos ou outros materiais - ou usando diferentes maneiras de movimentar o corpo, estruturações do espaço etc. Apresento a seguir o primeiro exercício do livro "Rítmica Métrica" (1967, p. 9):

$$
\begin{array}{ll}
\text { E 1a }- \text { - } 1 \text { pe-ex }^{3} & \\
\text { PI (posição inicial) } & \text { - lugar: em qualquer lugar da sala; } \\
& \text { - corpo: no chão, sentado. }
\end{array}
$$

A pessoa deve realizar o metro, batendo-o de 4 modos diferentes que devem ser executados, em sucessão direta:

$1^{\circ}$ modo: bater nas palmas;

$2^{\circ}$ modo:bater com os pés, no chão;

$3^{\circ}$ modo:bater com as palmas, no chão;

$4^{\circ}$ modo:bater o $1^{\circ}$ valor no $2^{\circ}$ modo, os valores restantes, no $1^{\circ}$.

Aplicar andamentos diferentes (de "lento" a "rápido"), conservando, porém, um mesmo andamento dentro de uma sucessão. Dar grande atenção ao relaxamento e à participação voluntária do corpo, na execução dos modos, para conseguir uma permanente elasticidade e vivência do ritmo.

Mostro a seguir a estrutura de um dos exercícios do livro "Proporção e Precisão: um método de rítmica com base em metros gregos", (GELEWSKI, 1986, pp. 29 a 31), que apresenta elaborações complexas, usando a orientação do espaço e a definição rítmica essencial.

Exercício oe - X pessoas - execução

Posição Inicial - lugar: conforme as conveniências do exercício; corpo: sentado ou de pé, a critério do instrutor.

Em perfeita sincronia com as indicações no desenho (5A), o instrutor colocará as plaquetas4 no chão, deixando em volta da formação algum espaço livre.

Com base neste conjunto de plaquetas, realizar as seguintes fases de exercício:
3.

$\mathrm{E} 1 \mathrm{a}=$ exercício $1 \mathrm{a} ; \mathrm{-}-\mathrm{=}$ espondeu; 1 pe = uma pessoa; ex $=$ execução.
4.

Neste livro, um dos materiais didáticos elaborados por Rolf foram as "plaquetas", que são dois cartões de tamanhos diferentes: um como longura e um outro como brevidade. Em meu trabalho escolhi um quadrado de $12 \mathrm{~cm}$, e o retângulo como o dobro do quadrado (24x12cm). Podemos usar cores diferentes para diversificar outros exercícios e distinguir outros grupos de trabalho. 
a - toda a turma: distribuindo as pessoas em volta da formação, de tal modo que cada uma possa ver toda a sequência das plaquetas, pedir que todas batam palmas em cada um dos valores, distinguindo bem as brevidades das longuras, num andamento médio a ser realizado com muita firmeza e apoiado em batidas de percussão produzidas pelo próprio instrutor (são exatamente 46 batidas, pois há dezoito brevidades e mais quatorze longuras, equivalendo as 28 brevidades). Começar no lado direito, percorrer a sequência uma só vez, terminando, pois, com a última longura de linha de baixo, no lado direito; trabalhar a sequência várias vezes seguidas, dando ênfase tanto à distinção clara de longuras e brevidades quanto ao fluxo ininterrupto das batidas;

b - toda a turma: realizar a sequência mais uma vez, em condições idênticas ao item anterior (a), invertendo-se porém, a sucessão, isto é, começando com a linha de baixo, no lado direito, prosseguir até chegar na longura final da linha de cima, no lado direito, a qual, na fase anterior (a), foi o começo; quanto ao resto, vale tudo o que foi dito para a realização da fase anterior (GELEWSKI, 1986, pp. 29 a 30).

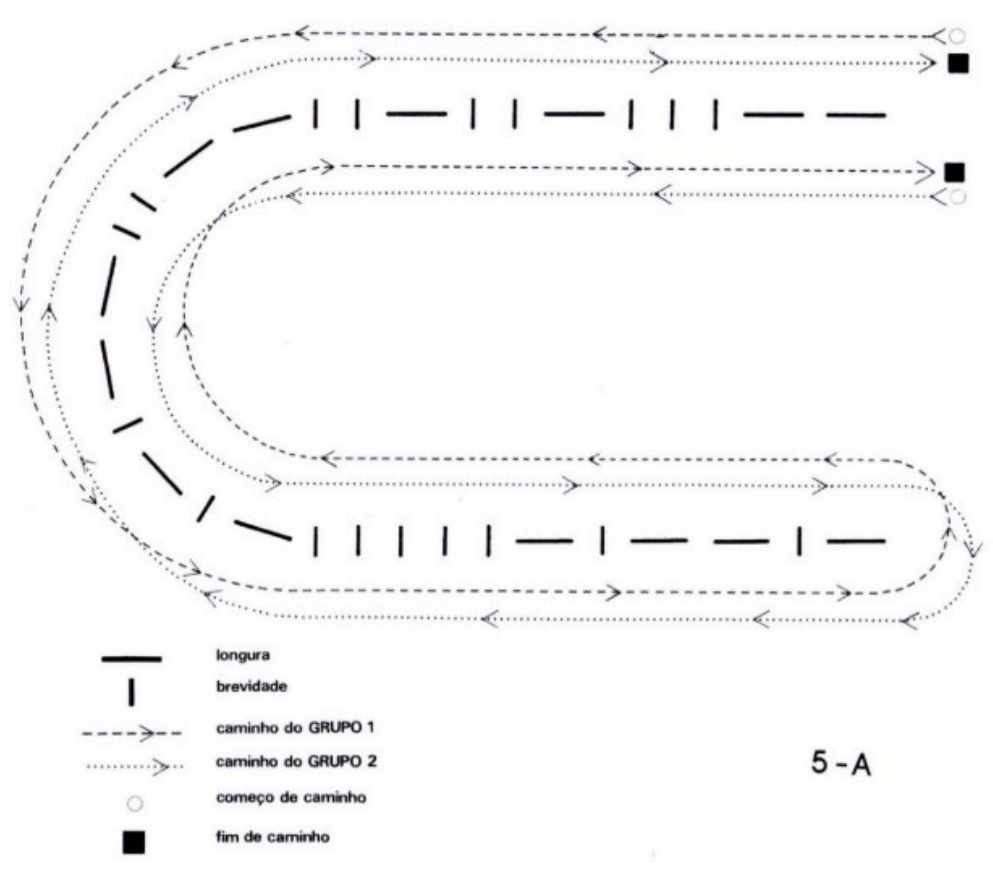

Figura 1.

"Proporção e Precisão" (GELEWSKI, 1986, p. 31).

\section{IV - Estudo do Espaço}

Rolf considerou em seu Estudo do Espaço três aspectos da dança:

1. As três Dimensões do Espaço

2. As Direções no Espaço

3. Caminho Reto e Curvo no Espaço

Em cada um desses aspectos Gelewski elaborou exercícios definidos e variados. Eles fazem parte de um texto (existente como uma apostila) que ele usava como um material didático básico nesta disciplina. 
Na Universitas, editora da Universidade Federal da Bahia, Rolf Gelewski publicou uma Separata (Janeiro/Abril 1970) com o título "Da unidade do espaço: algumas reflexões". Ele sempre buscou em suas disciplinas uma relação direta com a dimensão reflexiva e filosófica, buscando em seus alunos uma compreensão cada vez mais ampla e profunda do sentido humano e da vida. Relembrando meus estudos de Rudolf Laban e Mary Wigman, compreendo o quão próximo a relação e compreensão do espaço de Rolf está enraizada na visão deles. Apresento a seguir um extrato de suas reflexões.

Coisa alguma, forma alguma, nenhum movimento, nenhuma vida seria se o espaço não existisse. E, assim parece, o espaço não existiria se coisa alguma, forma alguma, nenhum movimento e nenhuma vida fosse. ...

Quem quereria negar que a infinidade do universo começa aos seus pés, quando abre a porta da sua casa? Que os muros do quarto em que está na verdade não o isolam da ininteligibilidade do espaço cósmico? Integrando cada quarto uma casa, cada casa uma rua, cada rua uma cidade, cada cidade um país, cada país um Continente, cada um dos nossos Continentes a terra, a terra nosso sistema solar, nosso sistema solar a via láctea, etc., etc., não somos assim, onde sempre for, participantes constitutivos do espaço total, pertencendo concretamente à sua incomensurabilidade? (GELEWSKI, 1971, p. 99).

Os três aspectos do espaço foram assim definidos em sua apostila:

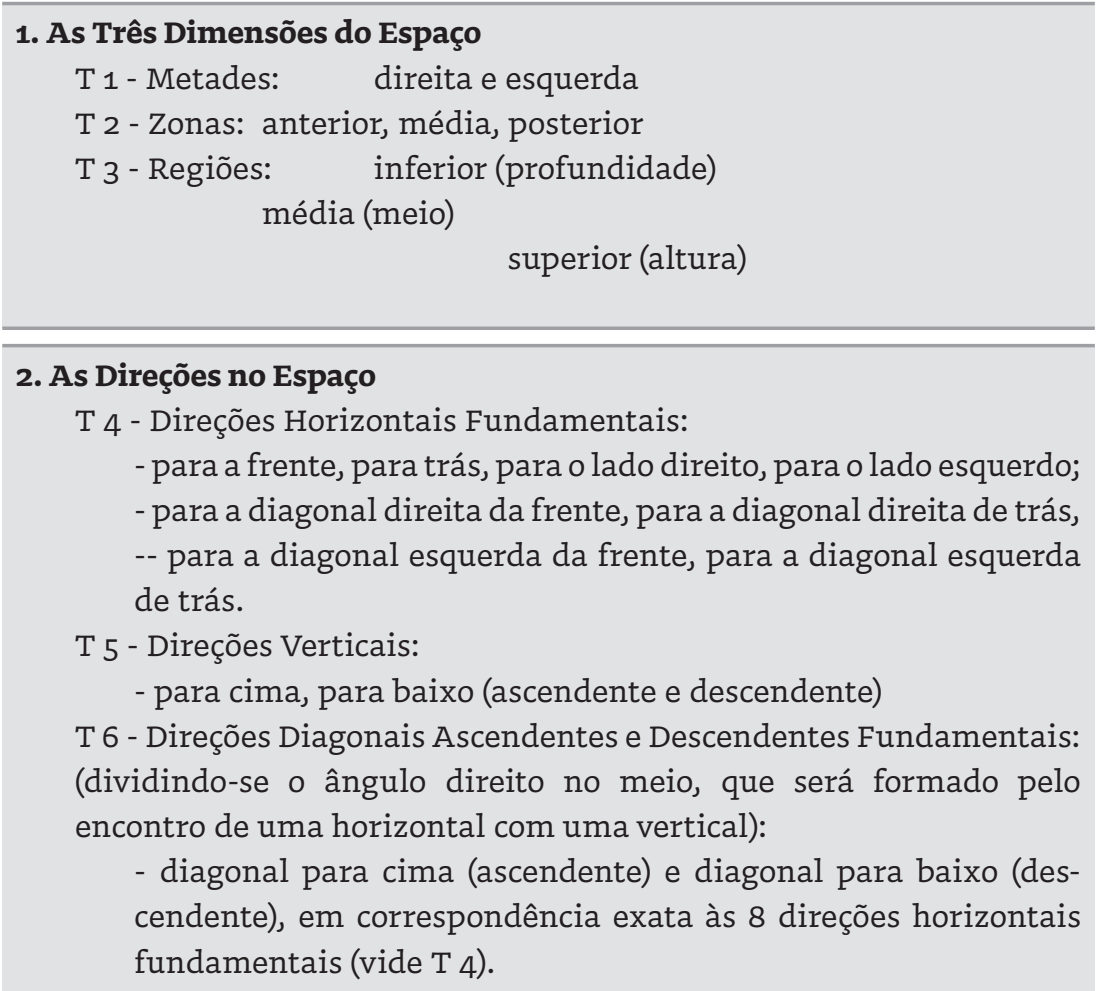




\section{Os Caminhos no Espaço}

a) O Caminho Reto no Espaço

$\mathrm{T} 7$ - Retas isoladas

T 8 - Retas interligadas e formações angulares abertas

T 9 - Formações angulares fechadas (triângulo, quadrado, etc.)

b) O Caminho Curvo no Espaço

$\mathrm{T} 10$ - curvas isoladas

$\mathrm{T} 11$ - curvas interligadas

$\mathrm{T} 12$ - espiral e círculo

Nas disciplinas "Prática de Dança I - ESPAÇO", e "Estudo do Movimento na Dança" que tenho lecionado no curso Licenciatura em Dança, na Escola de Belas Artes da UFMG, utilizo vários dos exercícios de Rolf sobre o espaço, seguindo a estrutura acima mencionada. Para termos uma melhor compreensão de como ele os elaborou, mostrarei um dos exercícios tirados desta apostila.

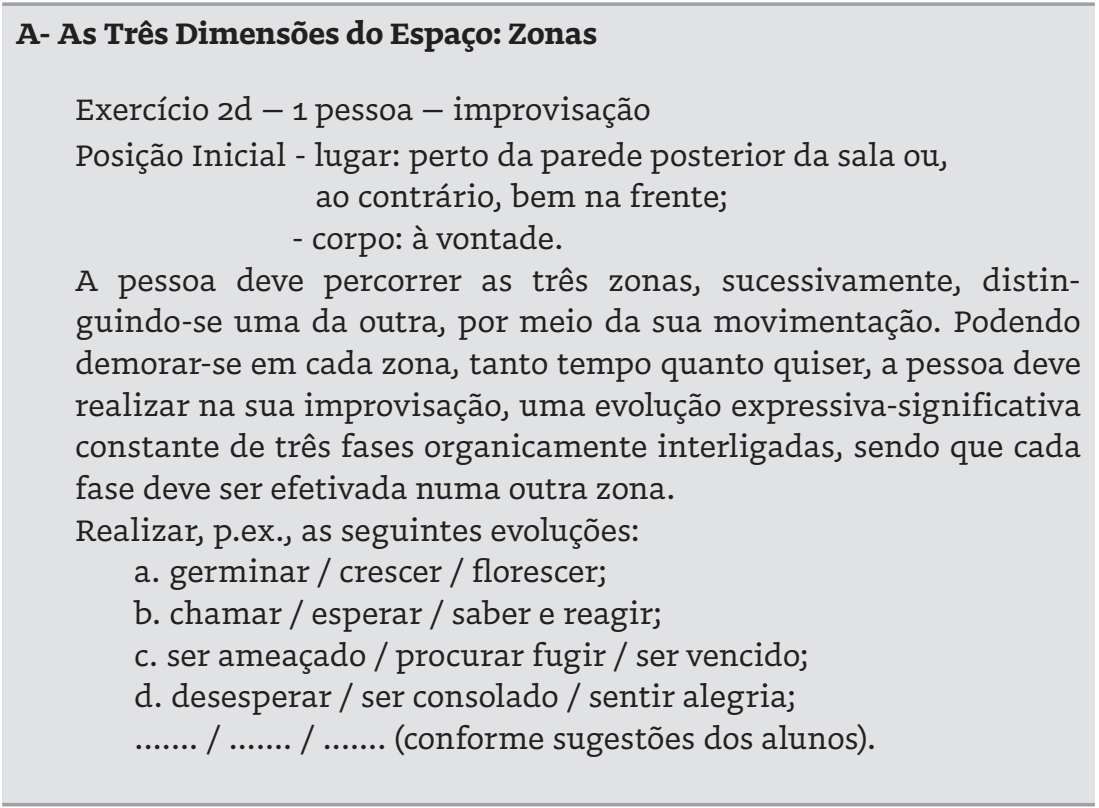

\section{V - Improvisação}

Gelewski publicou o livro "Ver, Ouvir, Movimentar-se" (1973a), reunindo e compilando a essência e a estrutura da disciplina Improvisação na Dança, criada por ele no Curso de Dança Contemporânea da UFBA. Ele apresenta dois métodos de improvisação na dança: Improvisação Estruturada e Improvisação Livre. Ao mesmo tempo, Rolf publicou "Estruturas Sonoras 1" (1973b) - um livro com uma fita cassete de músicas gravadas e selecionadas - que se associava às músicas especificamente 
apropriadas à estrutura metodológica de suas aulas de improvisação. Esses dois livros representam ainda hoje o melhor material didático que conheço para uma disciplina de improvisação em dança.

"Ver Ouvir Movimentar-se" (GELEWSKI, 1973a) apresenta dois métodos de improvisação na dança, descrevendo cada fase de cada um dos métodos passo a passo. Ambos os métodos se baseiam no uso de material musical. O primeiro, parte da exploração gradativa dos movimentos do corpo, com uma complexidade crescente, apoiada na exploração da estrutura da peça musical, do seu aspecto mais simples até o mais elaborado. A análise musical proposta acontece, porém, exclusivamente através do ouvir direto e concreto da peça musical, e não a partir de um conhecimento prévio da teoria musical convencional. O segundo método começa com uma improvisação completamente livre sobre uma peça musical, e se desenvolve para dentro de uma improvisação estruturada em conexão com aspectos estruturais tanto do movimento quanto da música com a qual se está trabalhando, para terminar novamente com outra improvisação completamente livre. Esta última improvisação livre acontece como o resultado da tomada de consciência por experimentação das estruturas pertinentes, de sua assimilação e, finalmente, do desprender-se delas, de seu abandono. Resumindo, temos três etapas:

- conscientização da estrutura da peça musical,

- assimilação da mesma por audição e movimentação do corpo,

- abnegação (abandono) de qualquer vinculação à estrutura.

Em "Ver, Ouvir, Movimentar-se" Rolf Gelewski formula os dois objetivos que ele almeja.

O objetivo direto deste método consta de um preparo básico do aluno para o trabalho como dançarino e como coreógrafo, preparo realizado especialmente pelo treinamento e desenvolvimento de sua sensibilidade, criatividade, inteligência e capacidade de reação e combinação, e ainda através de sua informação musical-cultural. O objetivo indireto situa-se mais na dimensão do humano, no sentido do crescimento e evolução do aluno como indivíduo: consiste na ligação dinâmica da consciência com regiões não-conscientes do ser e assim na unificação e intensificação dele (GELEWSKI, 1973a, p. 16).

O primeiro método conduz à improvisação estruturada e pode ser considerado como um processo preparatório ao trabalho coreográfico. O segundo método leva então à improvisação livre. Apesar de poder acontecer uma confrontação do aluno com o primeiro método, ela se intensificará e se tornará mais evidente no segundo. 
Baseado nos dois métodos desenvolvidos por Rolf Gelewski, apresentei em minha tese de doutorado (2010) a junção das duas fases do desenvolvimento deste processo de improvisação na dança. Através dos cursos de improvisação em dança que dei e organizei, esta união e elaboração dos dois métodos cumpriu melhor os propósitos do trabalho. Esta estrutura pode ser encontrada nos arquivos de doutorado da Unicamp: "Reconectando Corpo e Alma sobre o Processo de Improvisação e Criação em Dança" (BAETA, 2010). O mesmo texto faz também parte do meu livro "A Improvisação Integral na Dança" (2014) e, em alemão, "Integrale Tanzimprovisation" (2014).

O segundo livro, "Estruturas Sonoras 1" (GELEWSKI, 1973b) foi desenvolvido em conexão com o primeiro. Ele compreende 25 gráficos para 25 peças musicais, cujas gravações fazem parte da publicação. Esses gráficos ilustram e visualizam a estrutura musical das peças, fornecendo um apoio visual para o processo de audição dos dois métodos mencionados acima.

Estou surpreso que nesses quarenta anos de trabalho pedagógico com a dança, em contato direto com músicos e especialistas da dança de várias partes do mundo, nunca me deparei com um trabalho semelhante. Ele é muito simples tanto em sua base como em sua estrutura. Reproduzo a seguir o gráfico número 18 do seu livro (GELEWSKI, 1073a), que visualiza o "Minuet I e II" da "Partita Nr. 1 por piano" de Johann Sebastian Bach, numa interpretação de Glenn Gould.
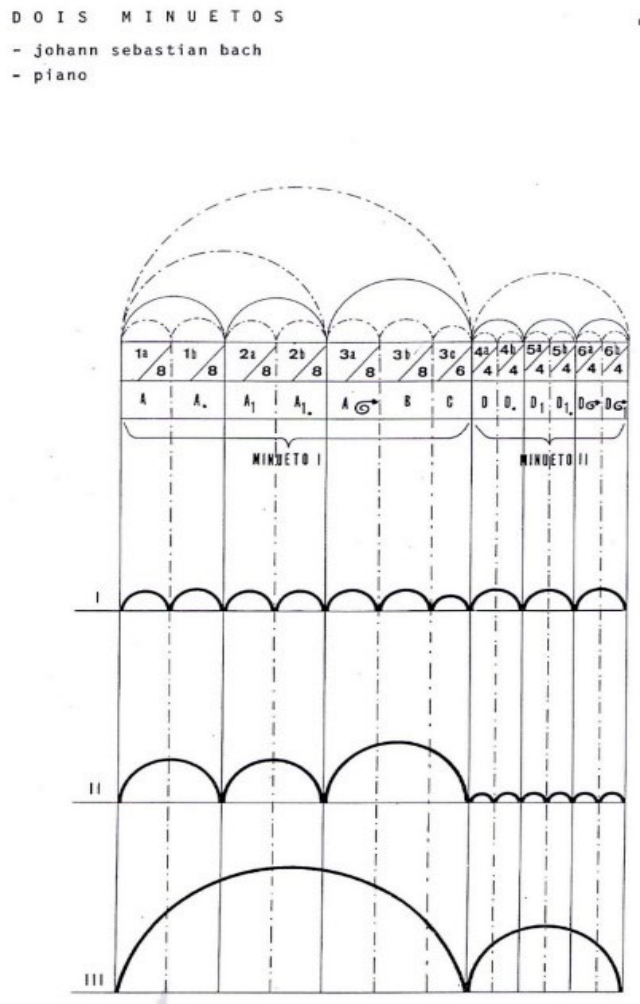
Menciono aqui esses dois livros, porque o processo apresentado neles constitui a base do meu trabalho em dança com música. São publicações infelizmente esgotadas, mas de um imenso valor pedagógico e de apoio no processo criativo em dança.

Acho importante acentuar que, na maioria dos casos, uma execução livre e ao mesmo tempo estruturada da dança como um todo só se alcança depois de um trabalho intensivo e diversificado com muitas repetições das fases do método sobre músicas as mais diversas, o que pode estender-se pelo período de vários anos. E permanecerá sempre um processo, sem meta fixa e sem fim. Trata-se, antes de tudo, de um pedaço do caminho que conduz a nós mesmos, à totalidade de nosso ser, o qual temos que percorrer. Cada processo significa ora uma vivência intensa e, assim, um grande passo adiante, ora um desvio ou uma estagnação. Esta troca é parte necessária da dinâmica do que é vivo. A orientação deve ser clara; o processo dinâmico do seu desenvolvimento, porém, é sempre descontínuo e não retilíneo.

\section{VI - Composição e Coreografia}

Na classificação pedagógica de Rolf, composição significa a definição e estruturação de uma criação coreográfica individual, ou um solo. Coreografia segue a mesma definição, mas em grupo - duas ou mais pessoas interagindo. Em suma:

- Composição: estudo ou trabalho coreográfico individual,

- Coreografia: estudo ou trabalho coreográfico em grupo.

Composição e coreografia representam uma criação e estruturação dos movimentos em dança. Obviamente a composição tem uma dinâmica e estrutura própria. A coreografia apresenta a mesma intenção de criação do movimento de dança, mas possui elementos diferentes pela possibilidade de usar mais pessoas no mesmo momento ou no mesmo espaço, como, por exemplo: blocos, espelhos, repetições ou variações de temas, trocas ou variações de lugares etc.

Seguindo a lista de disciplinas anteriormente apresentada - Técnica Corporal, Estudo Básico de Formas, Rítmica Métrica, Estudo do Espaço, e Improvisação - Rolf criou e elaborou métodos pedagógicos em todas essas disciplinas. Muitas vezes elaboramos as aulas dessas disciplinas exatamente como Composição ou Estruturação Coreográfica. Nos exercícios criados por ele, há muitos deles referentes à "Fixação", que representam "estudos de composição" (individual), ou "estudos de coreografia" (em grupo). Assim, podemos encontrar a metodologia de Rolf como composição e coreografia nos próprios materiais pedagógicos de seus livros e apostilas. 
Como parte do projeto de pesquisa encontrei nos arquivos da CASA um texto do Rolf com o título "Pesquisas Coreográficas" (Duo e Trio), apresentado no $1^{\circ}$ Encontro de Escolas de Dança do Brasil, realizado pelo Conselho Nacional de Cultura, em Curitiba, em 1962. Neste texto ele menciona:

Constatamos que a dança de duas pessoas só começa a tornar-se um duo, se um certo grau de concordância surge, por meio de coordenação espacial, temporal e formal dos movimentos, o que o duo, então, só é uma verdadeira unidade, se, entre os dois "partners", existe uma relação contínua.

Também no trio, deve ser criada uma unidade pela viva relação entre os "partners", mas, a entrada de uma terceira figura apresenta ao coreógrafo situações completamente novas.

No que se refere às relações das partes entre si que poderiam ser dadas como condição, tendo assim uma influência determinante na sua junção em trio, estão abertas todas as possibilidades - da concordância mais profunda até o isolamento (GELEWSKI, 1962, p. 7).

Além dos textos introdutórios e explicativos, constam nessa apostila exercícios estruturados, tanto do Duo como do Trio. Apresentarei a seguir uma explicação da estrutura básica do Duo, e um dos seus exercícios.

\section{DUO}

\section{A. Explicação}

Rolf divide o Duo em dois capítulos:

1. Nascimento da Relação

2. Situações Típicas
a. Simetria
b. Paralelismo
c. Imitação
d. Assimetria

Observação (tirada do texto): "Obra musical usada para os exercícios: Bela Bartók, Mikrokosmos, Vol.I (edição: Boosey \& Hawkes)”.

\section{B. Exercício}

Exercício $2-2$ pessoas - composição (música: nº15)

Elaborar uma sequência solística de movimentos e ensinar a mesma a cada pessoa, de maneira que as 2 pessoas executam, com absoluta igualdade, os mesmos movimentos; em relação ao espaço, a sequência deve ser apropriada para ser executada das três seguintes maneiras:

a - as pessoas executam a sequência na mesma direção, afastadas uma da outra, demonstrando assim movimentos paralelos, sendo, porém, que cada pessoa dança numa outra zona do espaço (p.ex., a $1^{\mathrm{a}}$ pessoa na zona anterior e a $2^{\mathrm{a}}$ na zona média);

$\mathrm{b}$ - como em a-, porém, na mesma zona e à mesma altura;

c - como em a-, porém, com estreita consciência das pessoas. 
Na minha compreensão, seguindo o conhecimento e a informação das pessoas que estudaram e trabalharam com ele (e levando em consideração a análise atual deste projeto de pesquisa), Rolf não apresentou nenhum trabalho escrito completo referente às disciplinas Composição e Coreografia. Minhas anotações e as que recebi da professora Dra. Elisabeth Bauch Zimmermann e Aryamani (1970 e 1971) seguem a orientação pedagógica que ele nos apresentou, e que são sem dúvida o esqueleto principal desta proposta pedagógica. Rolf criou o termo "mobis", representando "motivos de movimentação". Nele propunha estruturas didáticos tanto em improvisação, como em composição e coreografia, tais como: criação (invenção) de "mobis", multiplicação de "mobis", conjunção de "mobis". Em cada uma delas ele sugeria variações referentes a repetição, espelho, identificação ou oposição, uso de forma, espaço, ritmo, modificação da intensidade em cada elaboração dos "mobis".

O que ainda nos falta é elaborar, escrever e publicar nossa experiência concreta deste trabalho. Esta é uma das minhas perspectivas futuras, depois do fechamento deste de pesquisa de pós-doutorado atualmente em desenvolvimento.

\section{VII - Filosofia da Dança}

Esta disciplina foi criada por Rolf exclusivamente para o Curso de Dança da UFBA. Ele tinha a preocupação de favorecer os estudantes de dança, devido à grande parte de seus trabalhos físico-corporais, a desenvolverem a sua capacidade de pensar e refletir, a partir do uso de textos filosóficos, educativos e artísticos. Ele dava muita atenção à divulgação e comentários de textos relacionados à arte, dança e educação, visando a uma compreensão mais profunda da visão humana contemporânea. Meu primeiro curso com ele foi no $4^{\circ}$ Festival de Inverno da UFMG, em Ouro Preto (julho de 1970). No currículo constava a disciplina "Filosofia da Dança e a Educação". Para tal, Rolf compilou uma apostila com o título "Textos referentes à Filosofia da Dança e à Educação" (1970). Nela constavam textos de diversos autores, como Ernst Bloch, Pierre Teilhard de Chardin, Martin Buber, Sri Aurobindo, além de outros textos próprios do Gelewski. A palestra dele "Dança e Educação" feita por ele no "Festival Mirim", como parte do $4^{\circ}$ Festival de Inverno da UFMG, é parte desta apostila. Ele usou várias partes desta palestra em nossas leituras e discussões. Seguem-se extratos dela:

O próprio tema de minha palestra chama-se "Dança e Educação". 
É um tema específico, tão específico que acho necessário dizer primeiro algo sobre o significado da arte como recurso educativo; e antes disso, até, quero procurar apreender a essência da educação em si, perguntando pelos objetivos da última. Apenas desta maneira, parece-me, estaremos em condições de perceber qual a contribuição da arte e, em particular, da dança para a educação. É então a pergunta básica: "Quais os objetivos da educação?" (GELEWSKI, 1970, p. 15).

"O ser humano", diz o filósofo Ernst Bloch, "é aquilo que tem ainda muito diante de si. ... O verdadeiro no homem como no mundo, não está realizado, está esperando" (GELEWSKI, 1970, p. 17).

Em toda prática artística, o ser humano é chamado para participar com a inteireza de seu ser. Espontaneidade sensibilidade, criatividade e inteligência, concentração, controle e disciplina do físico, da dinâmica vital e das emoções, o sentido filosófico e outras qualidades são exercitadas e desenvolvidas, nas experiências artísticas criadoras e re-criadoras. Além disso, a arte é uma linguagem internacional, verdadeiramente apta para por o indivíduo em contato direto com os povos do mundo e suas culturas e, desta maneira, fazê-lo reconhecer seu lugar como integrante da Família Humana (GELEWSKI, 1970, pp. 18 a 19).

Em seus cursos na Escola de Dança da UFBA, a "Filosofia da Dança" constava regularmente como matéria optativa. Como bailarino do Grupo de Dança Contemporânea da UFBA, participei desta disciplina. Fiquei surpreso ao ver que muitos alunos de outros departamentos da universidade se interessavam por esta matéria; e não só alunos da arte - como teatro, música e artes plásticas e da dança - mas também educação, filosofia, medicina, sociologia e pedagogia. Uma apostila criada por ele nesta disciplina chamava-se: "Dança vista mais profundamente" (GELEWSKI, 1967), com textos de Adolf Portmann, Henri Bergson, Ram Gopal, Eugen Herriegel, Curt Sachs e outros. Nessas apostilas criadas por ele como material didático, ele deu muita atenção aos pensadores de diferentes países, culturas e épocas, orientais e ocidentais e também mantendo uma visão contemporânea educacional brasileira.

Concluo este capítulo com uma frase escolhida por Rolf como contracapa da Revista ANANDA, caderno especial III agosto 1974 (Casa Sri Aurobindo):

"O problema da expressão da beleza física é um problema espiritual" (A Mãe).

\section{Considerações Finais}

Cada um de nós que trabalhamos tão próximos de Rolf representamos um baú de informações, tanto corporal quanto 
mentalmente. As publicações, textos, gravações, fotos, filmes e materiais concretos são mais fáceis de serem encontrados e estudados, mas estas memórias mentais e de sentimentos e de consciência corporal são preciosidades únicas. Como isso se perde facilmente e com o tempo, estamos atentos e preocupados em manter e desenvolver nossas experiências com os valores metodológicos, didáticos e pedagógicos de Rolf Gelewski, e tão logo quanto possível, desenvolver possibilidades concretas de divulgações e publicações de seus trabalhos. Como dito antes, este artigo não está concluído como material pedagógico final referente ao trabalho didático do Rolf: a função é mostrar o grande potencial existente desses materiais, até então muito pouco usados. Fico feliz em observar que professores e pesquisadores da educação da dança estão pesquisando a riqueza do trabalho que Rolf criou e desenvolveu. Ele já é uma referência pedagógica de dança no Brasil e até mesmo em outros lugares do mundo.

A Profa. Dra. Katja Schneider, responsável pelos Departamentos de "Theater- und Tanzwissenschaft" - Ludwig Maxililians Universität - München (Ciência do Teatro e da Dança, Universidade Ludwig Maxililian de Munique), e Andreas Mascha, editor da "Verlag Andreas Mascha" (editora, com seu próprio nome), organizaram o simpósio internacional e interdisciplinar "Em Direção e Através: Transferências Culturais e Migrações Artísticas”, de 4 a 6 de abril de 2014, em Munique. O último dia foi reservado ao "Tributo a Rolf Gelewski", do qual participei. Além das palestras referentes ao tema, apresentei uma exposição de fotos de Rolf, no local do simpósio, e apresentei um recital de dança com o título "Improvisação Integral na Dança - uma jornada interna e transcultural". Minha palestra, no Tributo a Rolf Gelewski, teve também como título "A Improvisação Integral na Dança".

Termino este texto com a frase de Sri Aurobindo (1970), minha respiração de vida: "Mesmo o corpo deve lembrar-se de Deus". 


\section{REFERENNCIAS}

AUROBINDO, Sri. Savitri, Livro IX, Canto I, Sri Aurobindo Birth Centenary Library, vol. 29, Sri Aurobindo Ashram, Pondicherry, 1970, p. 707.

GELEWSKI, Rolf. Pesquisas Coreográficas (Duo e Trio). Apostila não publicada, apresentada no $1^{\circ}$ Encontro de Escolas de Dança do Brasil, em Curitiba, realizado pelo Conselho Nacional de Cultura. Salvador - BA: Universidade Federal da Bahia, 1962.

GELEWSKI, Rolf. Rítmica Métrica (Um método didático para o ensino de rítmica). Salvador - BA: UNIVERSITAS Universidade Federal da Bahia, 1967.

GELEWSKI, Rolf. Dança vista mais profundamente. Apostila de curso não publicada. Salvador - BA: Universidade Federal da Bahia, 1967.

GELEWSIKI, Rolf. Textos referentes à Filosofia da Dança e à Educação. Apostila não publicada, apresentada como material didático no $4^{\circ}$ Festival de Inverno da Universidade Federal de Minas Gerais. Salvador - BA: Universidade Federal da Bahia, 1970. GELEWSIKI, Rolf. Da unidade do espaço: algumas reflexões. Salvador - BA: UNIVERSITAS - Universidade Federal da Bahia, 1970.

GELEWSIKI, Rolf. Estudo Básico de Formas. Salvador - BA: UNIVERSITAS - Universidade Federal da Bahia, 1971.

GELEWSKI, Rolf. Ver, Ouvir, Movimentar-se. Salvador - BA: Nós Editora, 1973a.

GELEWSKI, Rolf. Estruturas Sonoras 1. Salvador - BA: Nós Editora, 1973b.

GELEWSIKI, Rolf. Proporção e Precisão: um método de rítmica com base em metros gregos. Salvador - BA: Casa Sri Aurobindo, 1986.

PASSOS, Juliana Cunha. Rolf Gelewski e a improvisação na criação em dança: formas, espaço e tempo. Curitiba: Editora Prismas, 2015.

PEREIRA, Paulo Baeta. Integrale Tanzimprovisation. München: Verlag Andreas Mascha, 2014.

PEREIRA, Paulo José Baeta. A Improvisação Integral na Dança. Campinas: Editora Medita, 2014.

PEREIRA, Paulo José Baeta. Reconectando Corpo e Alma: Sobre o Processo de Improvisação e Criação em Dança. 2010. Tese (Doutorado em Artes) Instituto de Artes, Universidade Estadual de Campinas, Campinas, 2010.

SCHAFNER, Carmen Paternostro. A Dança Expressionista Alemanha e Bahia. Salvador - Bahia: EDUFBA, 2012. 
ZIMMERMANN, Elisabeth Bauch. A Dança na formação do indivíduo: relacionando os métodos de criação em dança de Rolf Gelewski e Rudolf von Laban com temas da Psicologia Analítica Junguiana sobre a natureza humana. 2016. Tese (Livre Docência) - Instituto de Artes, Universidade Estadual de Campinas, Campinas, 2016. 